\title{
The Influence of Cosmetic Selection Attributes on Purchase Intention: Focusing on the Cosmetic Purchase in China
}

\author{
화장품선택속성이 구매의도에 미치는 영향: \\ 중국 온라인쇼핑의 화장품구매를 중심으로
}

Shuli Wang ${ }^{1}$, Hakyun Kim $^{2}$

왕서려 ${ }^{1}$, 김하균 ${ }^{2}$

${ }^{1}$ Master's Student, Division of Business, Pukyong National Univ., Korea, 1367920736@qq.com

${ }^{2}$ Professor, Division of Business, Pukyong National Univ., Korea, kimhk@pknu.ac.kr

Corresponding author: Hakyun Kim

\begin{abstract}
China's Internet access population has been increasing rapidly in recent years. Therefore, the number of mobile Internet users in China is increasing together with the Internet penetration rate. Internet access rate of Chinese mobile phone netizens maintains a large share. The number of cosmetics purchased by online shopping in China is also increasing a lot. Purchasing cosmetics continues to affect the purchasing power of online shopping. The purpose of the study is to analyze the selection and attributes of products that affect the purchase intention of Chinese online shopping cosmetics. Particularly, this study examined the effect of cosmetic selection attributes (quality, brand, design, price, advertisement) on customer satisfaction of Chinese online cosmetics consumers. In addition, the influence of consumer's purchase intention according to customer satisfaction was verified. This study used the statistical package SPSS 22.0 for basic statistical analysis of the questionnaire. For hypothesis verification, the centralized validity and discriminant validity were verified using the structural equation package Smart PLS 2.0. The summary of the study is as follows. Quality, brand, price, design and advertising influence the intention to purchase cosmetics in online shopping in China. The factors that determine the type of cosmetic selection attributes were classified into quality, price, brand, and design selection attributes. The results of the study are as follows. First, quality had a significant effect on customer satisfaction. Second, brand had a significant influence on customer satisfaction. Third, price had a significant effect on customer satisfaction. Fourth, design had a significant influence on customer satisfaction. Fifth, advertisement had a significant influence on customer satisfaction. Sixth, customer satisfaction had a significant influence on purchase intention.
\end{abstract}

Keywords: Online Shopping, Cosmetic Selection Attributes, Customer Satisfaction, Purchase Intention

요약: 중국의 인터넷접속 인구가 최근에 급격히 증가되고 있는 추세이다. 따라서 중국의 모바일 인터넷의 사용자 수도 크게 증가되고 있으며, 인터넷 보급률도 넓게 확대되고 있다. 계속 적으로 인터넷 사용자는 크게 증가되고 있으며, 특히 중국 휴대폰 네티즌의 인터넷 접속률이 크게 증가되고 있는 상황이다. 중국 온라인쇼핑의 화장품 구매량도 크게 증가되고

Received: March 13, 2021; 1st Review Result: April 28, 2021; 2nd Review Result: June 16, 2021

Accepted: July 31, 2021 
있으며, 중국에서 화장품의 구매도 온라인쇼핑의 화장품 구매력에 계속적으로 영향을 주고 있다. 본 연구는 화장품의 선택속성(품질, 브랜드, 디자인, 가격, 광고)이 중국 온라인 화장품의 소비자 구매의도에 미치는 영향을 살펴보았다. 또한 고객만족도에 따른 소비자의 구매의도 간의 영향을 검증하였다. 본 연구는 설문지의 기본통계분석을 위해 통계 패키지인 SPSS 22.0 을 사용하였다. 가설검증을 위해 구조방정식 패키지 Smart PLS 2.0 을 사용하여 집중타당성과 판별타당성을 검증하였다. 본 연구의 목적은 중국 온라인쇼핑 화장품의 구매의도에 미치는 상품의 선택과 속성을 분석하는 데 연구의 목적이 있다. 연구의 결과는 다음과 같다. 본 연구를 위해 화장품의 선택속성의 유형을 결정하는 요인으로 품질, 브랜드, 가격, 디자인 및 광고를 선택속성으로 나누었다. 첫째, 품질은 고객만족도에 유의한 영향을 미쳤다. 둘째, 브랜드는 고객만족도에 유의한 영향을 미쳤다. 셋째, 가격은 고객만족도에 유의한 영향을 미쳤다. 넷째, 디자인은 고객만족도에 유의한 영향을 미쳤다. 다섯째, 광고는 고객만족도에 유의한 영향을 미쳤다. 여섯째, 고객만족도는 구매의도에 유의한 영향을 미쳤다.

핵심어: 온라인 쇼핑, 화장품의 선택 속성, 고객만족도, 구매의도

\section{1. 서론}

2005년 이후로 중국 인터넷거래는 빠른 발전을 거쳐, 네티즌의 수는 기하급수적으로 증 가하고 있다. 전자 상거래와 성립된 거래의 숫자도 끊임없이 높아지고 있다. 중국 정부 에서는 인터넷의 기본적인 시설에 대해 끊임없이 강화되고 있으며, 중국 전체에 인터넷 을 보급시키기 위하여 계속적으로 노력하고 있다. 또한 중국 전체에 대한 인터넷 보장체 계를 엄격하게 관리하고 있다[1].

중국인터넷 권위기구인 중국인터넷 데이터센터에서는 제44차 “중국 인터넷발전통계보 고”를 발표했다[2]. 이 보고에의하면 “2019년 6월까지 중국의 모바일 인터넷 사용자 수” 는 8억 8400만 명에 달했다. 2018년 말 대비 2984만 증가, 중국 휴대폰 네티즌의 인터넷 접속률 $99.1 \%$ 이고, 또한 중국 온라인쇼핑의 화장품 구매량도 많이 증가하였다. 증가되면 서 화장품의 상품 속성도 온라인쇼핑의 화장품구매력에 영향을 끼치고 있다. 중국 화장 품 시장의 규모는 계속적으로 증가하고 있다. 중국에서 지속적인 경제성장으로 인한 소 득의 증가와 여성들의 자기자신에 대한 관심은 꾸준히 증가되고 있다[3]. 중국 내에서 화 장품을 온라인으로 구매를 하는 연령층은 주로 90 년대 이후세대이며, 90년대 이후세대는 대부분이 온라인을 통한 화장품 구매를 선호하였다. 알리바바는 빅데이터 분석을 통하여 중국 온라인 쇼핑몰의 사용자 중에서 90 년대 이후 세대가 전체의 $50 \%$ 에 달하며 소비액 전체의 $40 \%$ 를 차지한다고 분석하였다[4]. 중국에서 대표적인 온라인 쇼핑몰로 손꼽히는 사이트는 타오바오와 징동이다. 중국의 화장품 시장은 다양한 분류 방법이 있으나 대부 분 온라인 시장과 오프라인 시장으로 분리한다. 온라인 시장은 타오바오, 징동 등의 대형 웹사이트이며 오프라인 시장은 시장, 화장품 가계, 백화점, 대형마트 등으로 나눌 수 있 다. 중국의 화장품 시장은 다른 국가와 다르게 온라인 시장이 활성화되어 있다. 한국무역 협회는 중국의 전자 상거래 규모를 2018년 대비 $24.2 \%$ 의 성장한 7 조 5000 억 위안(약 1,218 조 원)으로 예상하고 있으며, 2020 년까지 $20 \%$ 내외의 성장률로 계속적으로 성장할 전망이다[5].

중국의 온라인 쇼핑몰은 계속 증가하고 있으며, 그 중에서 화장품 시장의 증가세는 폭 
발적이다. 기업이 중국 시장의 공략에서 시장규모와 잠재력으로 인해 진출을 시도한 기 업 중에서 실패한 기업이 많다. 따라서 중국 시장의 정확한 파악이 중요하다. 본 연구는 중국 온라인의 화장품을 중심으로 화장품의 상품속성(품질, 브랜드, 가격, 디자인, 광고)이 고객의 구매의도에 미치는 영향에 관하여 실증연구를 하였다. 중국 소비자가 기대하는 온라인쇼핑의 핵심 속성을 분석하고, 나아가 국내 기업의 중국 온라인 쇼핑몰의 진출 때 에 전략적 시사점을 주고자 한다. 화장품 상품속성을 통해서 중국 온라인 쇼핑몰의 화장 품 대한 만족도와 구매의도 관계를 기본적으로 탐구하는 데 목적이 있다.

\section{2. 이론적 배경}

\section{1 화장품의 선택속성}

화장품의 품질은 생산된 제품이나 서비스가 제공하는 것을 말한다[6]. 모든 사업에서의 품질은 다른 제품의 우월성으로도 해석할 수 있으며, 추구하는 목적에 부합하는 정도의 여부로 정의되기도 한다.

브랜드는 회사를 대표하는 지각된 이미지와 경험의 집합이다[7]. 좁은 의미로는 상품이 나 회사를 대표하는 로고, 구호, 상표, 표지 등을 의미한다. 이는 글자, 글자체, 숫자, 문 자 등의 간략화된 이미지인 로고, 색상을 포함한다. 회사의 브랜드 이미지는 소비자의 무 의식적인 기억 속에 각인되어 있으며, 브랜드 연상은 회사의 좋은 이미지에 반영된다.

가격은 경제, 경영, 사업적인 측면에서 용역, 물건, 제품, 자산의 금전적 가치를 나타내 는 것이다[8]. 제품, 상품 및 서비스 가격이란 소비자가 제품, 상품, 서비스를 한 단위로 구매하기 위해 지불해야 하는 것을 뜻한다. 가격은 제품, 상품 및 서비스에 대한 금전적 비용의 총액이다.

디자인은 상품에 대해 어떠한 목적을 가지고 설계하고 구현되는 것을 의미한다[9]. 즉, 기능성, 편리성, 아름다움을 함께 모두 갖추면서도 목적에 맞게 설계되어야 한다. 따라서 디자인은 다양하게 평가하는 것이 중요하다. 화장품의 디자인은 다른 제품과 차별화되어 브랜드 이미지가 소비자에게 큰 영향을 준다.

광고는 제품의 이름을 알리기 위한 수단이다. 회사의 제품(재화, 서비스)에 대하여 알리기 위한 목적을 갖는다[10]. 다양한 매체를 통해 가격을 지불하고 조직적이고 합리적인 매체를 통한 커뮤니케이션이다. 소비자는 브랜드를 통하여 본인의 자아와 동일시하게 느끼는 것이다.

\section{2 고객만족도}

고객만족도는 소비자가 기업들의 제품의 품질, 가격, 상품성, 서비스 등의 전반에 대한 만족 정도를 의미한다[11]. 고객만족은 긍정적으로 기업의 상품을 구매하기 위한 동기가 된다. 긍정적 구전, 칭찬, 추천 등은 소비자의 재 구매 행동의도로 이어진다. 기업들은 고객만족을 위한 노력에 최선을 다하고 있다. 소비자가 제품, 상품 및 서비스를 구매 시 즐거움, 기쁨 등은 고객만족도로 사용되기도 한다. 제품, 상품, 서비스를 얻기 위해 추가로 대가를 치러야 될 경우, 고객만족도는 떨어질 것이다. 고객만족도는 즐거움과 기쁜 느낌을 얻기 위한 것이다. 고객만족도 개념은 오래전부터 연구되어 왔다. 고객만족도와 소비자의 행동에 서로 밀접한 관계가 있다. 


\section{3 구매의도}

구매의도는 상품, 제품, 물건, 서비스 등을 구입하려는 소비자의 의도나 계획을 뜻한다. 일반적으로 상품을 구매하려는 의도로 제한되어 측정된다[12]. 소비자의 다양한 구매의사 결정 과정과 구매만족도에 영향을 미치는 요인에 대하여 많은 연구가 있었다. 구매의도를 측정하기 위해 제품에 대한 인식, 소비자에 대한 서비스, 구매에 대한 소비자의 위험 등이 구매의도 요인들이다[13]. 구매의도는 의지와 행동 사이의 소비자의 행동을 예측하기 위해 사용되는 변수이다. 소비자 구매의도는 상품, 제품, 서비스를 구매하려는 의도로 구매행동에 직접적인 영향을 미친다. 구매의도는 소비자들의 제품 구입함에 있어 구매의지가 있기에 기업에서는 중요한 평가의 대상이다.

\section{3. 연구설계}

\section{1 연구모형}

중국 온라인쇼핑의 화장품 구매의도는 화장품의 선택속성과 고객만족도의 영향을 받는다. 구매의도는 고개만족의 영향을 받으며, 고개만족도는 화장품 선택속성의 품질, 브랜드, 가격, 디자인과 광고 등에 영향을 받는다. 설문 조사기간은 2021년 12월부터 30 일간 지속되었다. 중국 온라인 영향의 화장품의 선택속성을 바탕으로 연구모형을 제시하면 [그림 1]과 같다.

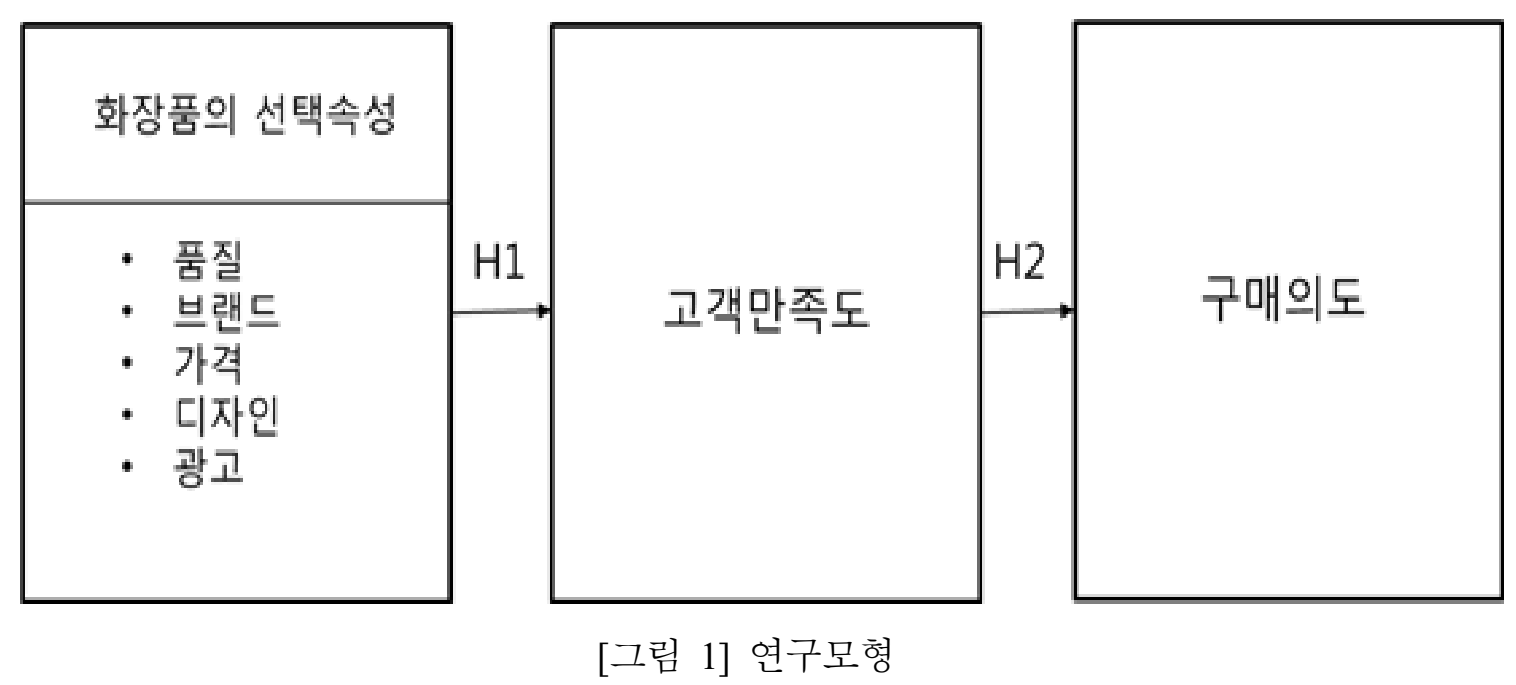

[Fig. 1] Research Model

\section{2 연구가설}

중국 온라인쇼핑 화장품의 구매의도를 미치는 선택속성은 품질, 브랜드, 가격, 디자인, 광고로 구분하였다. 선택속성과 고객만족도와 가설을 설정하면 다음과 같다. 
가설 $\mathrm{H1}$ 중국 온라인쇼핑 화장품의 선택속성은 고객만족도에 영향을 미칠 것이다.

가설 H1-1 화장품의 품질은 고객만족도에 영향을 미칠 것이다.

가설 H1-2 화장품의 브랜드은 고객만족도에 영향을 미칠 것이다.

가설 H1-3 화장품의 가격은 고객만족도에 영향을 미칠 것이다.

가설 H1-4 화장품의 디자인은 고객만족도에 영향을 미칠 것이다.

가설 H1-5 화장품의 광고는 고객만족도에 영향을 미칠 것이다

기업들의 공통적인 목표는 고객만족을 위해 최선의 노력을 하고 있다[11]. 구매의도 는 시장에서 판매되는 기업의 제품을 소비자가 구입하려는 의도이다. 일반적으로 기업의 모든 행위는 소비자가 상품을 구매하기 위한 의도이다[12].

가설 $\mathrm{H} 2$ 고객만족도는 구매의도에 영향을 미칠 것이다.

\section{4. 실증분석 및 결과}

설문지의 기본통계분석을 위해 통계 패키지인 SPSS 22.0을 사용하였다. 가설검정을 위해 구조방정식 패키지 Smart PLS 2.0을 사용하여 집중타당성과 판별타당성을 검증하였다. 요인 로딩 값, Cronbach' $\alpha$ 및 구성 신뢰도 (Composite Reliability) 및 각 요인의 평균분산추출 값 (Average Variance Extraction)을 검증했다. 0.6 이상의 요인 적재 값, Cronbach' $\alpha$ 값은 0.7 이상, 구성 신뢰도 값은 0.7 이상, 및 0.5 이상의 분산추출지수 값이 일반적으로 유효한 것으로 간주된다.

\section{1 자료수집 및 표본의 특성}

총 150 명의 사용자가 설문조사에 응답하였다. 기본통계조사를 살펴보면 다음과 같다. 응답자의 $44.2 \%$ 는 대학생이며, $55.8 \%$ 는 직장인, 공무원, 자유직 등이다. 상대적으로 일반인이 학생보다 높은 비율을 보인다. 연령에 있어서 주요 연령은 20-40대로 나타났다. 설문응답자에서 20 대가 $44.2 \%$ 로 제일 높았으며 다음은 30 대로 나타났다. 설문 응답자가 학생과 일반인이 주류를 이루는데 비해 전체적으로 연령대가 낮았다. 성별 분포를 살펴보면 여성 $90.4 \%$, 남성 $9.6 \%$ 로 분포되었다. 화장품의 특성으로 인해 남자의 분포가 낮은 것으로 나타났다. 특이한 점은 대학생의 경우가 화장품에 대하여 관심이 상당히 높은 것으로 나타났다.

\section{2 자료의 분석방법}

집중 타당성의 결과는 [표 1]과 같다. 판별타당성의 결과는 [표 2]와 같다.

[표 1] 신뢰도 및 집중 타당성 분석결과

[Table 1] Reliability and Internal Consistency Results

\begin{tabular}{|c|c|c|c|c|}
\hline 변수 & 요인 적재 값 & AVE & C. R. & Cronbach's $\alpha$ \\
\hline 품질 & 0.860 & 0.661 & 0.853 & 0.743 \\
\hline
\end{tabular}




\begin{tabular}{|c|c|c|c|c|}
\hline & 0.762 & & & \\
\hline & 0.815 & & & \\
\hline \multirow{3}{*}{ 브랜드 } & 0.863 & \multirow{3}{*}{0.781} & \multirow{3}{*}{0.914} & \multirow{3}{*}{0.861} \\
\hline & 0.906 & & & \\
\hline & 0.883 & & & \\
\hline \multirow{3}{*}{ 가격 } & 0.856 & \multirow{3}{*}{0.703} & \multirow{3}{*}{0.877} & \multirow{3}{*}{0.789} \\
\hline & 0.820 & & & \\
\hline & 0.839 & & & \\
\hline \multirow{3}{*}{ 디자인 } & 0.636 & \multirow{3}{*}{0.663} & \multirow{3}{*}{0.852} & \multirow{3}{*}{0.742} \\
\hline & 0.915 & & & \\
\hline & 0.865 & & & \\
\hline \multirow{3}{*}{ 광고 } & 0.844 & \multirow{3}{*}{0.672} & \multirow{3}{*}{0.859} & \multirow{3}{*}{0.757} \\
\hline & 0.719 & & & \\
\hline & 0.887 & & & \\
\hline \multirow{3}{*}{ 고객만족도 } & 0.904 & \multirow{3}{*}{0.805} & \multirow{3}{*}{0.925} & \multirow{3}{*}{0.879} \\
\hline & 0.909 & & & \\
\hline & 0.879 & & & \\
\hline \multirow{3}{*}{ 구매의도 } & 0.895 & \multirow{3}{*}{0.784} & \multirow{3}{*}{0.915} & \multirow{3}{*}{0.862} \\
\hline & 0.891 & & & \\
\hline & 0.869 & & & \\
\hline
\end{tabular}

[표 2] 상관관계 및 판별 타당성 분석결과

[Table 2] Correlation and Discriminant Validity

\begin{tabular}{|c|c|c|c|c|c|c|c|c|}
\hline 변수 & AVE & 품질 & 브랜드 & 가격 & 디자인 & 광고 & 고객만족도 & 구매의도 \\
\hline 품질 & 0.661 & $\mathbf{0 . 8 1 3}$ & & & & & & \\
\hline 브랜드 & 0.782 & 0.741 & $\mathbf{0 . 8 8 4}$ & & & & & \\
\hline 가격 & 0.703 & 0.757 & 0.793 & $\mathbf{0 . 8 3 8}$ & & & \\
\hline 디자인 & 0.663 & 0.294 & 0.181 & 0.276 & $\mathbf{0 . 8 1 4}$ & & & \\
\hline
\end{tabular}




\begin{tabular}{|c|c|c|c|c|c|c|c|c|}
\hline 광고 & 0.672 & 0.664 & 0.540 & 0.551 & 0.450 & $\mathbf{0 . 8 1 9}$ & & \\
\hline 고객만족도 & 0.805 & 0.757 & 0.780 & 0.799 & 0.140 & 0.574 & 0.897 & 0.886 \\
\hline 구매의도 & 0.784 & 0.756 & 0.751 & 0.773 & 0.241 & 0.664 & 0.735 & 0.886 \\
\hline
\end{tabular}

\section{3 연구 모형의 검증}

구조 모형은 Smart PLS 2.0을 사용하였으며 구조 모형을 통해서는 연구 모형의 변수들 간의 경로 계수와 결정 계수(R2)결과 값을 도출하였다. R2값이 0.26이상이면 적합도가 높은 편이며, 0.26 0.13이면 중간이다. 0.13이하는 적합도가 낮은 것으로 표시할 수 있다. 고객만족도(0.749)과 구매의도(0.541)에 대한 결정 계수(R2)값은 상으로 나타났다.

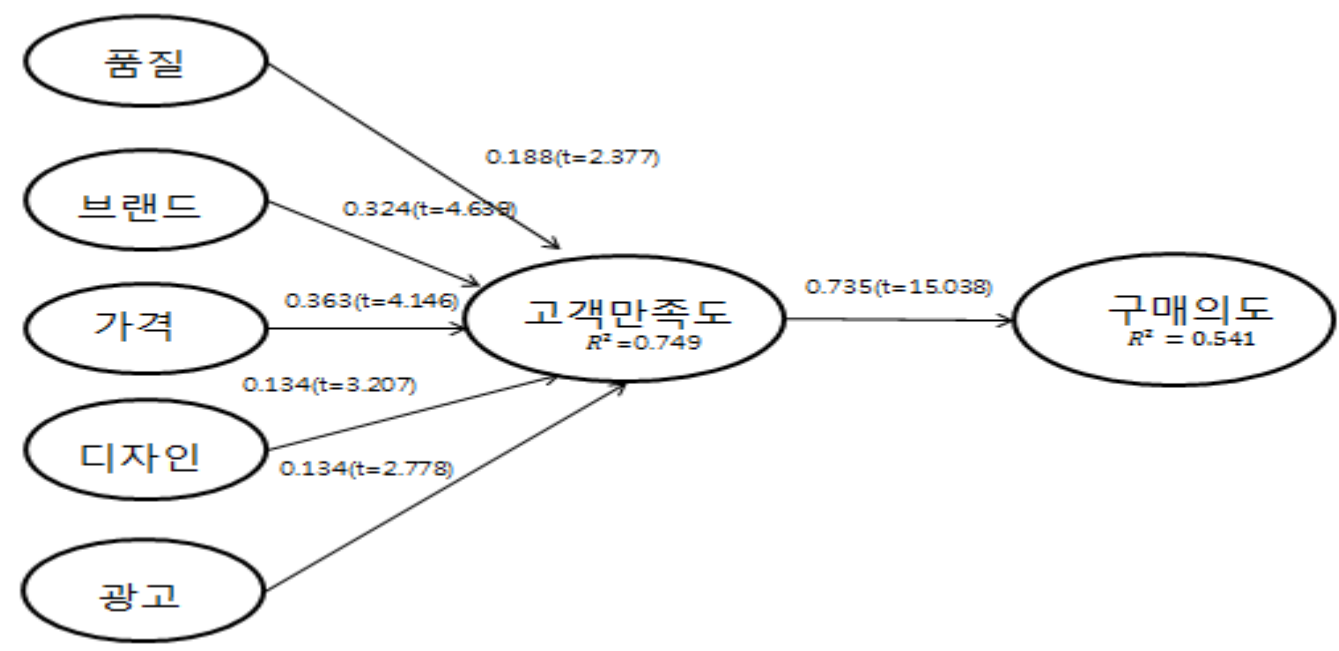

[그림 2] 구조 모형 분석결과

[Fig. 2] The Results of Research Model

제안한 가설 $\mathrm{H} 1, \mathrm{H} 2$ 는 채택되었다. 첫째, 가설 H1-1의 “품질은 고객만족도에 영향을 미칠 것이다"라는 가설은 채택되었다. 품질과 고객만족도 $(\beta=-0.188, \mathrm{t}=2.377, \mathrm{p}<0.05)$ 은 유의한 영향을 미치는 것으로 나타났다. 이는 화장품의 선택 속성에 품질은 고객만족도에 영향을 준다는 것이다. 둘째, 가설 H1-2의 “브랜드는 고객만족도에 영향을 미칠 것이다"라는 가설은 채택되었다. 품질과 고객만족도 $(\beta=0.324, \mathrm{t}=4.639, \mathrm{p}<0.05)$ 은 유의한 영향이 있는 것으로 나타났다. 이는 화장품의 선택 속성에 브랜드는 고객 만족도에 영향을 준다는 것이다. 셋째, 가설 H1-3의 “가격은 고객만족도에 영향을 미칠 것이다"라는 가설은 채택되었다. 가격과 고객만족도 $(\beta=0.363, \mathrm{t}=4.146, \mathrm{p}<0.05)$ 은 유의한 영향을 미치는 것으로 나타났다. 넷째, 가설 H1-4의 “디자인은 고객만족도에 영향을 미칠 것이다"라는 가설은 채택되었다. 디자인과 고객만족도 $(\beta=-0.134, \mathrm{t}=3.207, \mathrm{p}>0.05)$ 은 무의미한 영향을 미치는 것으로 나타났다. 다섯째, 가설 H1-5의 “광고는 고객만족도에 
영향을 미칠 것이다"라는 가설은 채택되었다. 광고와 고객만족도 $(\beta=0.134, \mathrm{t}=2.778$, $\mathrm{p}<0.05)$ 는 유의한 영향을 미치는 것으로 나타났다. 여섯째, 가설 H2-1의 “고객만족도는 구매의도에 영향을 미칠 것이다”라는 가설은 채택되었다. 고객만족도와 구매의도 $(\beta=0.735$, $\mathrm{t}=15.038, \mathrm{p}<0.05)$ 는 유의한 영향을 미치는 것으로 나타났다.

[표 3] 가설검정 결과 요약

[Table 3] Results of Hypothesis Tests for the Research Model

\begin{tabular}{|c|c|c|c|}
\hline 가설 경로 & 표준화 계수( $(\beta)$ & t-value & 채택 유무 \\
\hline H1-1: 품질-고객만족도 & 0.188 & 2.377 & 채택 \\
\hline H1-2: 브랜드-고객만족도 & 0.324 & 4.639 & 채택 \\
\hline H1-3: 가격-고객만족도 & 0.363 & 4.146 & 채택 \\
\hline H1-4: 디자인-고객민족도 & 0.134 & 3.207 & 채택 \\
\hline H1-5: 광고-고객만족도 & 0.134 & 2.778 & 채택 \\
\hline H2-1: 고객만족도-구매의도 & 0.735 & 15.038 & \\
\hline
\end{tabular}

\section{5. 결과}

본 연구는 중국 온라인쇼핑의 화장품 선택속성 (품질, 브랜드, 가격, 디자인, 광고)이 고 객 만족도과 구매의도에 어떤 영향을 주는지 알아보기 위한 실증연구이다. 중국 온라인 화장품의 선택속성, 고객만족도, 구매의도 대한 기존문헌을 정리하였다. 또한, 기존연구를 바탕으로 중국 온라인시장의 화장품 선택속성, 고객만족도, 구매의도 대한 연구 모형과 연구 가설을 설정하였다. 본 연구의 실증분석 결과를 요약하면 아래와 같다. 첫째, 기존 의 중국 온라인 화장품의 선택속성이 고객만족도에 영향을 미친다. 가설 $\mathrm{H} 1$ 은 채택되었 다. H1-1 품질은 고객만족도에 유의한 영향을 미쳤다. H1-2 브랜드는 고객만족도에 유의한 영향을 미쳤다. H1-3 가격은 고객만족도에 유의한 영향을 미쳤다. H1-4 디자인은 고객만족 도에 유의한 영향을 미쳤다. H1-5 광고는 고객만족도에 유의한 영향을 미쳤다. 둘째, 고객 만족도는 구매의도에 유의한 영향을 미쳤다는 가설 $\mathrm{H} 2$ 는 채택되었다.

본 연구를 통하여 중국 온라인쇼핑의 화장품 선택속성에서 규명된 것은 다음과 같다. 중국 온라인 화장품 시장에서 화장품의 선택속성 (품질, 브랜드, 가격, 디자인, 광고)의 변 화는 구매의도를 미칠 수 있다는 것이다. 연구의 시사점은 다음과 같다. 첫째, 중국 온라 인 화장품 선택속성에 관한 연구에서 구매의도를 고려해야 한다. 구매의도를 온라인 화 장품 선택속성과 특성을 나타내는 요인에는 품질, 브랜드, 가격, 디자인, 광고 등의 모든 요인이 유의한 결과가 보여주듯이 구매의도 특성에 대한 보다 체계적이고 자세한 연구가 필요하다. 또한, 모든 요인이 고객만족도에 유의한 영향을 미침으로 고객만족도에 관한 연구의 확대가 필요하다. 구매의도를 촉진하려는 기업은 온라인 쇼핑에서 판매한 화장품 
의 품질, 브랜드, 가격, 디자인, 광고 등을 향상시키야 한다. 이러한 노력이 브랜드 이미 지를 높일 수 있다. 이러한 화장품 선택 속성이 구매의도와 고객만족도의 다양한 조화를 통해서 구매의도의 촉진이 가능하다. 둘째, 화장품의 선택속성은 고객만족도를 통하여 발 전적으로 구매의도를 촉진하기 위해서는 품질, 브랜드, 가격, 디자인, 광고 등이 중요한 요인임을 밑바탕으로 기업 전략이 세워져야 한다. 따라서 구매의도에서 고객만족도에 관 한 연구는 향후 세밀하게 진행되어야 한다. 구매의도의 촉진하기 위해 자세한 요인들을 살펴보고, 실질적으로 문제해결을 할 수 있는 연구가 앞으로 진행되어야 할 것이다.

본 연구를 기반으로 중국 온라인 쇼핑의 화장품 선택속성 (품질, 브랜드, 가격, 디자인, 광고), 고객만족도, 구매의도에 대한 새로운 모형을 제안하게 되었다. 모형에 대해 실증적으로 분석함으로써 구매의도를 대상으로 연구한 결과를 확인할 수 있게 되었다.

화장품의 선택속성은 고객만족도를 미치고, 온라인 소비자들 구매 활동은 고객 만족도로부터 영향을 받음으로써, 고객의 구매의도에 도움을 줄 수 있을 것으로 예상한다.

본 연구의 시사점은 다음과 같다. 중국은 인터넷 사용자가 급증하면서, 디지털 경제를 미래 성장동력으로 판단하고 있다. 중국 온라인 쇼핑몰과 전자상거래 등의 고객 간의 마켓플레이스를 집중적으로 육성하고 있다. 하지만 다양한 장애 요인(전자상거래, 온라인 쇼핑몰, 인프라 등의 미숙으로 시장잠재력보다 발전속도가 미비하다. 중국 사용자들이 온라인 쇼핑몰이용 시에 중요하게 여기는 속성을 제시하고자 한다. 한국기업이 중국 시장 진출할 때 전략 수립에 중요한 가이드가 되었으면 한다.

\section{References}

[1] K. Oh, A Study on the Development Plan of Chinese Internet Shopping Mall, Woosong University, Master's Thesis, (2019)

[2] http://www.cac.gov.cn/2019-08/30/c_1124939590.htm, China Internet Development Statistics Report, Aug 30 (2019)

[3] 2019 Chinese cosmetics market forecast by keywords, KOTRA BEIJING Trade Center report, (2019)

[4] https://www.chainnews.com/articles/785432444566.htm, China Financial News, May 27 (2019)

[5] China Online Shopping Market Status and Implications, Korea International Trade Association (KITA) Market Report, (2019)

[6] B. Kim, The Influence of Service Habits on Purchasing at Coffee Shops: Focused on Female College Students, The Journal of the Korea Contents Association, (2015), Vol.15, No.11, pp.447-455, DOI: 10.5392/JKCA.2015.15.11.447

[7] Kevin Lane Keller, Strategic Brand Management, (4th Edition), Pearson, (2013)

[8] X. Kim, B. Park, A Study on Price Sensitivity and Satisfaction after Purchase in Internet Shopping Mall, Journal of the Korean Home Economics Association, (2003), Vol.41, No.9, pp.69-83, UCI: G704-000012.2003.41.9.011

[9] Y. Xu, Comparative Study on Chinese-Korean Basic Cosmetic Package Design, Kangwon National University, Master's Thesis, (2014)

[10] J. L. Aaker, Dimensions of Brand Personality, Journal of Marketing Research, (1997), Vol.34, No.3, pp.347-356, DOI: https://doi.org/10.1177/002224379703400304

[11] https://news.joins.com/article/41358, JoongAng Ilbo, What is customer satisfaction? Mar 9 (2019)

[12] J. H. Kwon, S. Y. Kim, The Effects of Crisis Communication Strategy and Timeliness on a Corporation's Brand Equity and Negative Dimensions of Organization-Public Relationships, Korean Journal of Journalism \& Communication 
The Influence of Cosmetic Selection Attributes on Purchase Intention: Focusing on the Cosmetic Purchase in China

Studies, (2018), Vol.62, No.1, pp.165-198, DOI: 10.20879/kjjcs.2018.62.1.006

[13] S. L. Jarvenpaa, P. A. Todd, Consumer Reactions to Electronic Shopping on the World Wild Web, International Journal of Electronic Commerce, (1996), Vol.2, No.2, pp.59-88, DOI: https://doi.org/10.1080/10864415.1996.11518283 